\title{
Caracterização do perfil retrospectivo do dirigente esportivo de clube de futebol profissional da primeira divisão, entre os anos 2003 e 2007
}

\author{
Paulo Henrique Azevêdo \\ Rubens Eduardo Nascimento Spessoto
}

\author{
Faculdade de Educação Física \\ Universidade de Brasília (UnB) \\ Brasil
}

\begin{abstract}
RESUMO
O propósito desta investigação foi o de analisar a evolução do perfil sócio-econômico e cultural retrospectivo dos gestores das organizações esportivas profissionais que atuaram na primeira divisão de futebol do Distrito Federal, Brasil, durante as edições do Campeonato Brasiliense, entre os anos de 2003 e 2007. Como perfil foram entendidas as características gerais, aspectos e caráter delimitados neste trabalho. Foi uma pesquisa do tipo descritiva e retrospectiva, que utilizou como instrumentos de investigação o questionário e a análise documental de dados, onde foram estudados os 19 dirigentes máximos que administraram os seus clubes nestas competições, quanto às seguintes variáveis: gênero, faixa etária, nível de escolaridade, estado civil, ocupação principal, renda mensal pessoal e cargo ocupado no clube esportivo. Os resultados apontaram que esses gestores são indivíduos do gênero masculino, casados, na faixa etária de 46 a 55 anos, que têm ocupação principal de funcionário público, com curso superior incompleto ou completo, renda mensal entre US\$1422,64 a mais de US\$1778,31, ocupantes do cargo de presidente de seus respectivos clubes esportivos.
\end{abstract}

Palavras-chave: esporte, gestão do esporte, futebol, dirigentes esportivos

\begin{abstract}
Retrospective characterization of the profile of football proleague sport managers, between the years 2003 and 2007

The purpose of this investigation was to examine the evolution of the social, economical and cultural profiles of the managers of the professional sports organizations that participated in the first division soccer league of the Federal District, Brazil, during the championship's editions between 2003 and 2007. As for profile were considered general characteristics, aspects and character as defined in this study. It was an descriptive and backwards research, that used a questionnaire and documentary analysis as instruments of survey, in which the 19 leaders who managed their clubs in these competitions were studied, concerning the following variables: gender, age group, level of schooling, marital status, main occupancy, monthly personal income and occupation in the sports club. The results showed that this managers are male, married, with complete or incomplete university education, have monthly income between US $\$ 1422.64$ to above US\$1778.31, all of them being presidents of their respective sports clubs.
\end{abstract}

Key-words: sports, sports management, soccer, sports managers 


\section{INTRODUÇÃO}

O profissionalismo no futebol evolui substancialmente nas relações de trabalho entre profissionaisatletas e os clubes esportivos, mas será que o mesmo acontece na administração dos clubes que mantêm atividade esportiva profissional em seus quadros? À frente da gestão de clubes de futebol, indivíduos possuem responsabilidade que vão além da mero cumprimento burocrático empresarial. Muito se questiona sobre quem são esses gestores do esporte e quais as suas características gerais. O Campeonato Brasiliense de Futebol, realizado no Distrito Federal, é um dos vinte e sete campeonatos, onde as equipes disputam o título estadual (no caso, Distrital) e vagas para a participação na Copa do Brasil, segunda mais importante competição do futebol brasileiro. Os clubes de futebol do Distrito Federal são constituídos, em grande parte, por exjogadores de equipes das mais diversas regiões do país e não é muito representativa a presença de atletas formados nas categorias de base dessas equipes. A despeito do pouco tempo de vida da Capital Federal, o seu futebol profissional já começa a ter boa representatividade nos cenários regional e nacional, sendo que os melhores resultados começaram a aparecer ao final dos anos 1990. O Brasiliense Futebol Clube Taguatinga chegou em 2002 à final da Copa do Brasil; subiu para primeira divisão do Campeonato Brasileiro em 2004, mas caiu em 2005 para a segunda divisão, onde permanece até hoje. A Sociedade Esportiva do Gama já participou da primeira divisão do Campeonato Brasileiro (mais recentemente no quadriênio 1999-2000-2001-2002); foi rebaixada consecutivamente (em 2002 e 2003), chegando à terceira divisão, onde permaneceu por uma temporada, tendo retornado para a segunda divisão, onde também se encontra atualmente.

O futebol do Distrito Federal não possui como característica um modelo de gestão competitivo; também não se verifica a existência de incentivos financeiros significativos e, por isso, as estruturas físicas e os recursos humanos existentes não são aqueles considerados adequados ao sucesso esportivo das equipes. Os melhores resultados esportivos obtidos nos últimos anos contrastam com os problemas de ordem organizacional, de ausência ou atraso de pagamentos, denúncias de sonegação de impostos e utilização de recursos provenientes de fontes duvidosas. Nesse sentido, torna-se imprescindível o papel do gestor esportivo, como elemento fundamental para que os clubes adquiram as condições essenciais para o sucesso financeiro e esportivo. Bastos(1) conclui "ser necessário um direcionamento temático, uma diversificação e um incremento geral nos estudos, pesquisas, publicações, intercâmbios entre o meio acadêmico e os profissionais que atuam na área da Administração Esportiva".

Para Drucker(2), a administração é independente da propriedade, de títulos e de poder. Ela é uma função objetiva e deve ser fundamental na responsabilidade pelo desempenho; é profissional - a administração é uma função, uma disciplina, uma tarefa a ser executada; e os administradores são os profissionais que exercitam esta disciplina, desempenham suas funções e executam as tarefas. Já não é mais relevante se o administrador é também o proprietário; a propriedade é acidental ao trabalho principal: administrar. Segundo Motta e Bresser-Pereira(3), nas organizações burocráticas é necessário haver o administrador profissional, pessoa esta que é altamente qualificada, um especialista. Quando se for escolher o administrador da organização, deve-se levar em consideração as competências do profissional e não as relações hereditárias. Coloca ainda que o administrador profissional tem seu cargo como atividade principal, e não faz dela meramente um "bico" ou "passa tempo", como ocorre diversas vezes com os dirigentes dos clubes esportivos, segundo o descrito abaixo: “...Ele não é administrador por acidente, subsidiariamente, como o eram os nobres dentro da administração palaciana, ou como ainda o são os conselheiros e mesmo os diretores de um clube esportivo"(3). $\mathrm{O}$ administrador esportivo, para realizar um bom trabalho, precisa ter desenvolvido algumas características, competências e acima de tudo conhecimento. Em estudo realizado, Correa ${ }^{(4)}$, apresenta algumas competências julgadas importantes, que deveriam ser trabalhadas internamente com os dirigentes dos clubes de futebol. Encabeçam a lista: conhecimentos gerais, conhecimentos específicos do ambiente profissional e conhecimentos procedimentais, além de outras competências. Segundo o autor, grande parte dos clubes de futebol estão em estágio inicial no processo de construção dessas qualidades 
tão importantes para exercer uma boa gestão. Para Pires e Lopes(5), a questão a ser colocada é sobre qual a formação básica necessária para a atuação no mundo do desporto, especificamente na área da gestão. Para estes pesquisadores, é indispensável uma formação inicial em gestão do desporto, pois a capacitação tradicional já não atende às exigências sociais. De maneira conclusiva, afirmam que "as actuais gerações de dirigentes hão-de ser responsabilizadas por não terem sido capazes de promover um modelo sustentado de desenvolvimento do desporto que não comprometesse as práticas desportivas das gerações futuras".

A gestão realizada pelos dirigentes tradicionais de clubes e federações de futebol tem sido indicada como a causa maior do não aproveitamento pleno do potencial econômico do futebol brasileiro, principalmente nos denominados agentes diretos - clubes e federações; somada aos problemas estruturais da economia e das diferenças de renda per capita entre o Brasil e os principais países que investem no futebol como atividade econômica(6). Zouain e Pimenta(7), sugerem como perfil profissional genérico do gestor esportivo, um profissional que tenha habilidades com enfoque nas áreas de administração (técnicas gerenciais, conhecimento fiscal, programação de eventos), comunicação e relacionamento humano (gestão de pessoas, marketing e vendas, habilidades de comunicação); entendendo não ser fácil estabelecer um perfil genérico ao profissional de gestão esportiva brasileira, num ambiente que apresenta profissionais com formação muito heterogênea.

Souza(8), ao analisar as seguintes entidades esportivas brasileiras: Federação de Triatlo do Distrito Federal, Federação Metropolitana de Handebol, Federação Brasiliense de Voleibol, Federação Brasiliense de Ginástica e Federação de Desportos Aquáticos do Distrito Federal, verificou que todos os gestores (presidentes) destas instituições trabalhavam voluntariamente, sem qualquer tipo de remuneração, assim como os demais colaboradores que garantiam o funcionamento daquelas estruturas. Constatou que os presidentes possuíam curso superior completo, sendo que vinte por cento destes também haviam realizado pós-graduação. Mais da metade, ou seja, $60 \%$ dedicavam a até 4 horas diárias à sua federação, tempo insuficiente para se administrar esse tipo de organização.

Azevêdo, Barros e Suaiden(9) realizaram pesquisa onde foram estudados os dirigentes máximos dos dez clubes que participaram do Campeonato Brasiliense da primeira divisão de futebol profissional, no ano de 2001. A investigação permitiu traçar um perfil sócio-econômico e cultural desses dirigentes e em termos estatísticos foram utilizadas medidas de associação para variáveis qualitativas levantadas em questionários aplicados a estes dirigentes. No que se refere ao perfil dos dirigentes dos clubes, eles eram homens católicos, casados e recebiam mais de US\$2060,53 por mês; possuíam o ensino fundamental, tinham, em média, 45 anos e meio; trabalhavam como funcionários públicos e empresários, que acumulam com as atribuições de dirigentes dos clubes que presidiam; nenhum deles era profissional de gestão de suas entidades de futebol, embora afirmassem ter muito ou total poder de decisão sobre as questões.

Em 2001, os clubes de futebol profissional da primeira divisão do Distrito Federal possuíam administração centralizada, gestão respaldada na "paixão" pelo futebol, parceiros comerciais inconsistentes, predominância dos assuntos internos, falta de planejamento e distância de ações estratégicas. Por isso, ainda não haviam adotado uma gestão profissional em suas entidades(10).

\section{Objetivo}

Analisar a evolução do perfil sócio-econômico e cultural dos gestores das organizações esportivas profissionais que atuaram na primeira divisão de futebol do Distrito Federal, Brasil, durante as edições do Campeonato Brasiliense, entre os anos de 2003 e 2007.

\section{MATERIAL E MÉTODOS}

Foi realizada uma pesquisa descritiva com pesquisa de campo realizada no local de atuação onde ocorreu o fenômeno investigado. No mesmo sentido do que a pesquisa realizada por Azevêdo, Barros e Suaiden ${ }^{(9)}$, que estudou o perfil dos dirigentes que atuaram na mesma competição, especificamente no ano 2001, esta investigação realizou um estudo retrospectivo, abrangendo o período 2003-2007. 
Quadro 1. Clubes participantes do Campeonato Brasiliense da $1^{a}$ divisão entre os anos 2003 e 2007

\begin{tabular}{|c|c|c|c|c|}
\hline \multicolumn{5}{|l|}{ Ano Base } \\
\hline 2003 & 2004 & 2005 & 2006 & 2007 \\
\hline ARUC* & Bandeirante & Bandeirante* & Brasiliense & Brasiliense \\
\hline Bandeirante & Brasiliense & Brasiliense Ceilândia & Capital* & Ceilândia \\
\hline Brasiliense & Brazlândia* & CFZ & Ceilândia & Dom Pedro II \\
\hline Brazlândia & Ceilândia & Dom Pedro II & $\mathrm{CFZ}^{*}$ & Esportivo \\
\hline Ceilândia & CFZ & Gama & Dom Pedro II & Gama \\
\hline CFZ & Dom Pedro II & Guará & Gama & Luziânia* \\
\hline Dom Pedro II & Gama & Luziânia & Guará* & Paranoá* \\
\hline Gama & Guará & Paranoá & Luziânia & Unaí/Itapuã \\
\hline Guará & Luziânia & Santa Maria* & Paranoá & \\
\hline Luziânia-G0 & Paranoá* & Sobradinho* & Unaí/ltapuã & \\
\hline Sobradinho* & Sobradinho & Unaí/Itapuã & & \\
\hline Unaí-MG & Unaí & & & \\
\hline
\end{tabular}

*Clubes rebaixados para a segunda divisão

Os instrumentos utilizados na pesquisa de campo foram o questionário e a análise documental de dados obtidos na Federação Brasiliense de Futebol e nos sítios eletrônicos da Internet.

Foram estudados os dezenove dirigentes (presidentes), dos dezesseis clubes (Quadro 1) que disputaram, em uma ou mais edições, a primeira divisão do Campeonato Brasiliense de Futebol Profissional, entre os anos de 2003 e 2007, analisando as seguintes variáveis:

- Gênero;

- Faixa etária;

- Nível de escolaridade;

- Estado civil;

- Ocupação principal;

— Renda mensal pessoal; e

- Cargo ocupado no clube esportivo.

\section{Representação da frequência relativa dos dados encontrados}

As frequências relativas dos fenômenos observados são representadas como frações na forma $\mathrm{a} / \mathrm{b}$, onde $a$ é o número de ocorrências do fenômeno em questão e $b$ é o número de observações realizadas, e lê-se " $a$ de $b$ ". A justificativa para tal escolha é a grande possibilidade incidência de erros de arredondamento, quando da utilização de porcentagem, decorrente do uso de números pequenos de observações (e consequentemente de ocorrências), que geram dízimas periódicas. Para fins de formatação adequada das tabelas será usada a representação Fr para a Frequência Relativa aqui explicada.

\section{RESULTADOS}

Dos 16 clubes estudados, 13 não mudaram os seus presidentes (13/16) e 3 mudaram o seu principal dirigente (3/16) (Tabela 1$)$.

\begin{tabular}{cl|l|l}
$\begin{array}{c}\text { Tabela 1. Situação de } \\
\text { troca ou permanência } \\
\text { do dirigente máximo } \\
\text { do clube - 2003-2007 }\end{array}$ & Sobre a troca ou não do dirigente & Quantidade & Frequência Relativa \\
\cline { 2 - 4 } & Clubes que não trocaram o presidente & 13 & $13 / 16$ \\
\cline { 2 - 4 } & Clubes que trocaram o presidente & 03 & $03 / 16$ \\
\cline { 2 - 4 } & Total & 16 & $16 / 16$ \\
\hline
\end{tabular}




\begin{tabular}{l|l|l}
\hline Clubes que trocaram o dirigente & Quantidade & Frequência Relativa \\
\hline Clubes que trocaram uma vez & 02 & $2 / 3$ \\
\hline Clubes que trocaram duas vezes & 01 & $1 / 3$ \\
\hline Total & 03 & $3 / 3$ \\
\hline
\end{tabular}

Tabela 3. Distribuição das Frequências dos Dirigentes, segundo o Gênero

\begin{tabular}{|c|c|c|c|c|c|c|c|c|c|c|}
\hline \multirow{2}{*}{ Gênero } & \multicolumn{2}{|c|}{2003} & \multicolumn{2}{|c|}{2004} & \multicolumn{2}{|c|}{2005} & \multicolumn{2}{|c|}{2006} & \multicolumn{2}{|c|}{2007} \\
\hline & $\mathbf{n}$ & $\mathrm{Fr}$ & $\mathbf{n}$ & $\mathrm{Fr}$ & $\mathbf{n}$ & $\mathrm{Fr}$ & $\mathrm{n}$ & $\mathrm{Fr}$ & $\mathbf{n}$ & $\mathrm{Fr}$ \\
\hline Masculino & 12 & $12 / 12$ & 11 & $11 / 12$ & 11 & $11 / 12$ & 9 & $9 / 10$ & 7 & $7 / 8$ \\
\hline Feminino & 0 & $0 / 12$ & 1 & $1 / 12$ & 1 & $1 / 12$ & 1 & $1 / 10$ & 1 & $1 / 8$ \\
\hline Total & 12 & $12 / 12$ & 12 & $12 / 12$ & 12 & $12 / 12$ & 10 & $10 / 10$ & 8 & $8 / 8$ \\
\hline
\end{tabular}

Tabela 4. Distribuição, segundo faixa etária [frequências relativa [Fr] e absoluta [n]]

\begin{tabular}{|c|c|c|c|c|c|c|c|c|c|c|}
\hline \multirow{2}{*}{ Faixa Etária } & \multicolumn{2}{|c|}{2003} & \multicolumn{2}{|c|}{2004} & \multicolumn{2}{|c|}{2005} & \multicolumn{2}{|c|}{2006} & \multicolumn{2}{|c|}{2007} \\
\hline & $\mathbf{n}$ & $\mathrm{Fr}$ & $\mathbf{n}$ & $\mathrm{Fr}$ & $\mathbf{n}$ & $\mathrm{Fr}$ & $\mathrm{n}$ & $\mathrm{Fr}$ & $\mathbf{n}$ & $\mathrm{Fr}$ \\
\hline Até 25 anos & 0 & $0 / 12$ & 0 & $0 / 12$ & 0 & $0 / 12$ & 0 & $0 / 10$ & 0 & $0 / 8$ \\
\hline De 26 a 35 anos & 1 & $1 / 12$ & 1 & $1 / 12$ & 2 & $2 / 12$ & 1 & $1 / 10$ & 0 & $0 / 8$ \\
\hline De 36 a 45 anos & 3 & $3 / 12$ & 2 & $2 / 12$ & 1 & $1 / 12$ & 2 & $2 / 10$ & 3 & $3 / 8$ \\
\hline De 46 a 55 anos & 6 & $6 / 12$ & 7 & $7 / 12$ & 7 & $7 / 12$ & 7 & $7 / 10$ & 5 & $5 / 8$ \\
\hline De 56 a 65 anos & 2 & $2 / 12$ & 1 & $1 / 12$ & 1 & $1 / 12$ & 0 & $0 / 10$ & 0 & $0 / 8$ \\
\hline Mais de 65 anos & 0 & $0 / 12$ & 1 & $1 / 12$ & 1 & $1 / 12$ & 0 & $0 / 10$ & 0 & $0 / 8$ \\
\hline Total & 12 & $12 / 12$ & 12 & $12 / 12$ & 12 & $12 / 12$ & 10 & $10 / 10$ & 8 & $8 / 8$ \\
\hline
\end{tabular}

Sobre os clubes que trocaram o gestor (Tabela 2), dois tiveram dois e um teve três diferentes dirigentes máximos, no período. Duas equipes que mudaram o gestor foram rebaixadas, em algum desses anos.

\section{Gênero}

Foi possível observar que no período correspondente aos anos de 2003 a 2007 o número de times partici- pantes da primeira divisão do campeonato diminuiu, porém, a proporção de dirigentes masculinos manteve-se em grande parte do período, como observado na Tabela 3.

\section{Faixa Etária}

Foi observada maior ocorrência de dirigentes inseridos nas faixas etárias superiores a 36 anos, com des- 
Tabela 5. Distribuição, segundo nível de escolaridade [frequências relativa [Fr] e absoluta [n]]

\begin{tabular}{|c|c|c|c|c|c|c|c|c|c|c|}
\hline \multirow{2}{*}{ Faixa Etária } & \multicolumn{2}{|c|}{2003} & \multicolumn{2}{|c|}{2004} & \multicolumn{2}{|c|}{2005} & \multicolumn{2}{|c|}{2006} & \multicolumn{2}{|c|}{2007} \\
\hline & $\mathbf{n}$ & $\mathrm{Fr}$ & $\mathbf{n}$ & $\mathrm{Fr}$ & $\mathbf{n}$ & $\mathrm{Fr}$ & $\mathbf{n}$ & $\mathrm{Fr}$ & $\mathbf{n}$ & $\mathrm{Fr}$ \\
\hline Ensino fundamental incompleto & 2 & $2 / 12$ & 2 & $2 / 12$ & 1 & $1 / 12$ & 0 & $0 / 10$ & 1 & $1 / 8$ \\
\hline Ensino fundamental completo & 0 & $0 / 12$ & 0 & $0 / 12$ & 0 & $0 / 12$ & 1 & $1 / 10$ & 0 & $0 / 8$ \\
\hline Ensino médio incompleto & 0 & $0 / 12$ & 0 & $0 / 12$ & 0 & $0 / 12$ & 2 & $2 / 10$ & 0 & $0 / 8$ \\
\hline Ensino médio completo & 6 & $6 / 12$ & 6 & $6 / 12$ & 3 & $3 / 12$ & 0 & $0 / 10$ & 2 & $2 / 8$ \\
\hline Curso superior incompleto & 1 & $1 / 12$ & 1 & $1 / 12$ & 3 & $3 / 12$ & 3 & $3 / 10$ & 1 & $1 / 8$ \\
\hline Curso superior completo & 3 & $3 / 12$ & 3 & $3 / 12$ & 5 & $5 / 12$ & 4 & $4 / 10$ & 4 & $4 / 8$ \\
\hline Total & 12 & $12 / 12$ & 12 & $12 / 12$ & 12 & $12 / 12$ & 10 & $10 / 10$ & 8 & $8 / 8$ \\
\hline
\end{tabular}

Tabela 6. Distribuição, segundo estado civil [frequências relativa [Fr] e absoluta [n]]

\begin{tabular}{|c|c|c|c|c|c|c|c|c|c|c|}
\hline \multirow{2}{*}{ Estado Civil } & \multicolumn{2}{|c|}{2003} & \multicolumn{2}{|c|}{2004} & \multicolumn{2}{|c|}{2005} & \multicolumn{2}{|c|}{2006} & \multicolumn{2}{|c|}{2007} \\
\hline & $\mathbf{n}$ & Fr & $\mathbf{n}$ & $\mathrm{Fr}$ & $\mathbf{n}$ & $\mathrm{Fr}$ & $\mathbf{n}$ & $\mathrm{Fr}$ & $\mathbf{n}$ & $\mathrm{Fr}$ \\
\hline Solteiro (a) & 2 & $2 / 12$ & 2 & $2 / 12$ & 3 & $3 / 12$ & 1 & $1 / 10$ & 1 & $1 / 8$ \\
\hline Casado (a) & 9 & $2 / 12$ & 8 & $8 / 12$ & 7 & $7 / 12$ & 6 & $6 / 10$ & 5 & $5 / 8$ \\
\hline Divorciado (a) & 0 & $0 / 12$ & 0 & $0 / 12$ & 0 & $0 / 12$ & 1 & $1 / 10$ & 1 & $1 / 8$ \\
\hline Viúvo [a] & 1 & $1 / 12$ & 1 & $1 / 12$ & 1 & $1 / 12$ & 1 & $1 / 10$ & 0 & $0 / 8$ \\
\hline Outro & 0 & $0 / 12$ & 1 & $1 / 12$ & 1 & $1 / 12$ & 1 & $1 / 10$ & 1 & $1 / 8$ \\
\hline Total & 12 & $12 / 12$ & 12 & $12 / 12$ & 12 & $12 / 12$ & 10 & $10 / 10$ & 8 & $8 / 8$ \\
\hline
\end{tabular}

Tabela 7. Distribuição, segundo ocupação principal [frequências relativa [Fr] e absoluta [n]]

\begin{tabular}{|c|c|c|c|c|c|c|c|c|c|c|}
\hline \multirow{2}{*}{ Ocupação Principal } & \multicolumn{2}{|c|}{2003} & \multicolumn{2}{|c|}{2004} & \multicolumn{2}{|c|}{2005} & \multicolumn{2}{|c|}{2006} & \multicolumn{2}{|c|}{2007} \\
\hline & $\mathbf{n}$ & $\mathbf{F r}$ & $\mathbf{n}$ & Fr & $\mathbf{n}$ & $\mathbf{n}$ & $\mathbf{n}$ & $\mathrm{Fr}$ & $\mathbf{n}$ & $\mathrm{Fr}$ \\
\hline Funcionário Público & 5 & $5 / 12$ & 4 & $4 / 12$ & 6 & $6 / 12$ & 5 & $5 / 10$ & 3 & $3 / 8$ \\
\hline Empresário & 2 & $2 / 12$ & 2 & $2 / 12$ & 2 & $2 / 12$ & 2 & $2 / 10$ & 2 & $2 / 8$ \\
\hline Profissional Liberal & 2 & $2 / 12$ & 3 & $3 / 12$ & 2 & $2 / 12$ & 1 & $1 / 10$ & 1 & $1 / 8$ \\
\hline Funcionário de empresa privada & 2 & $2 / 12$ & 2 & $2 / 12$ & 1 & $1 / 12$ & 1 & $1 / 10$ & 1 & $1 / 8$ \\
\hline Aposentado & 0 & $0 / 12$ & 0 & $0 / 12$ & 0 & $0 / 12$ & 0 & $0 / 10$ & 0 & $0 / 8$ \\
\hline Outra & 1 & $1 / 12$ & 1 & $1 / 12$ & 1 & $1 / 12$ & 1 & $1 / 10$ & 1 & $1 / 8$ \\
\hline Total & 12 & $12 / 12$ & 12 & $12 / 12$ & 12 & $12 / 12$ & 10 & $10 / 10$ & 8 & $8 / 8$ \\
\hline
\end{tabular}


Tabela 8. Distribuição, segundo renda mensal pessoal [frequências relativa [Fr] e absoluta [n]]

\begin{tabular}{|c|c|c|c|c|c|c|c|c|c|c|}
\hline \multirow{2}{*}{ Renda mensal pessoal [US\$] } & \multicolumn{2}{|c|}{2003} & \multicolumn{2}{|c|}{2004} & \multicolumn{2}{|c|}{2005} & \multicolumn{2}{|c|}{2006} & \multicolumn{2}{|c|}{2007} \\
\hline & $\mathbf{n}$ & $\mathrm{Fr}$ & $\mathbf{n}$ & $\mathrm{Fr}$ & $\mathbf{n}$ & $\mathrm{Fr}$ & $\mathbf{n}$ & $\mathrm{Fr}$ & $\mathbf{n}$ & $\mathrm{Fr}$ \\
\hline Até US\$ 355,66 & 0 & $0 / 12$ & 1 & $1 / 12$ & 1 & $1 / 12$ & 1 & $1 / 10$ & 2 & $2 / 8$ \\
\hline Mais de US $\$ 355,66$ até US\$ 711,32 & 1 & $1 / 12$ & 1 & $1 / 12$ & 0 & $0 / 12$ & 0 & $0 / 10$ & 0 & $0 / 8$ \\
\hline Mais de US\$ 711,32 até US\$1066,98 & 2 & $2 / 12$ & 2 & $2 / 12$ & 2 & $2 / 12$ & 1 & $1 / 10$ & 0 & $0 / 8$ \\
\hline Mais de US\$1066,9 até US\$1422,64 & 2 & $2 / 12$ & 1 & $1 / 12$ & 1 & $1 / 12$ & 2 & $2 / 10$ & 2 & $2 / 8$ \\
\hline $\begin{array}{l}\text { Mais de US\$1422,64 até US\$ } \\
1778,31\end{array}$ & 2 & $2 / 12$ & 1 & $1 / 12$ & 2 & $2 / 12$ & 2 & $2 / 10$ & 1 & $1 / 8$ \\
\hline Mais de US $\$ 1778,31$ & 5 & $5 / 12$ & 6 & $6 / 12$ & 6 & $6 / 12$ & 4 & $4 / 10$ & 3 & $3 / 8$ \\
\hline Total & 12 & $12 / 12$ & 12 & $12 / 12$ & 12 & $12 / 12$ & 10 & $10 / 10$ & 8 & $8 / 8$ \\
\hline
\end{tabular}

Tabela 9. Distribuição, segundo cargo no clube [frequências relativa [Fr] e absoluta (n]]

\begin{tabular}{lllllllllll}
\hline \multirow{2}{*}{ Ocupação no Clube } & $\mathbf{2 0 0 3}$ & \multicolumn{2}{c}{$\mathbf{2 0 0 4}$} & & $\mathbf{2 0 0 5}$ & $\mathbf{2 0 0 6}$ & & $\mathbf{2 0 0 7}$ \\
\cline { 2 - 10 } & $\mathbf{n}$ & $\mathbf{F r}$ & $\mathbf{n}$ & $\mathbf{F r}$ & $\mathbf{n}$ & $\mathbf{F r}$ & $\mathbf{n}$ & $\mathbf{F r}$ & $\mathbf{n}$ & $\mathbf{F r}$ \\
\hline Presidente & 8 & $8 / 12$ & 9 & $9 / 12$ & 11 & $11 / 12$ & 8 & $8 / 10$ & 6 & $6 / 8$ \\
Vice-Presidente & 3 & $3 / 12$ & 2 & $2 / 12$ & 0 & $0 / 12$ & 0 & $0 / 10$ & 0 & $0 / 8$ \\
Diretor & 1 & $1 / 12$ & 1 & $1 / 12$ & 1 & $1 / 12$ & 1 & $1 / 10$ & 2 & $2 / 8$ \\
Vice-diretor & 0 & $0 / 12$ & 0 & $0 / 12$ & 0 & $0 / 12$ & 0 & $0 / 10$ & 0 & $0 / 8$ \\
Conselheiro & 0 & $0 / 12$ & 0 & $0 / 12$ & 0 & $0 / 12$ & 1 & $1 / 10$ & 0 & $0 / 8$ \\
Outra & 0 & $0 / 12$ & 0 & $0 / 12$ & 0 & $0 / 12$ & 0 & $0 / 10$ & 0 & $0 / 8$ \\
\hline Total & 12 & $\mathbf{1 2 / 1 2}$ & $\mathbf{1 2}$ & $\mathbf{1 2 / 1 2}$ & $\mathbf{1 2}$ & $\mathbf{1 2 / 1 2}$ & $\mathbf{1 0}$ & $\mathbf{1 0 / 1 0}$ & $\mathbf{8}$ & $\mathbf{8 / 8}$ \\
\hline \hline
\end{tabular}

taque para a faixa de 46 a 55 anos de idade, que concentra, em todos os anos, pelo menos metade do número de dirigentes.

Observa-se até o ano de 2006, aumento da frequência relativa às faixas 36 a 45 anos e 46 a 55 anos.

\section{Nível de Escolaridade}

Observa-se que até 2004 (Tabela 5), tem-se maior concentração de dirigentes com nível escolaridade até o ensino médio completo. Enquanto a partir do ano de 2005, é claro o aumento nos dirigentes com nível de instrução mais avançado; em 2007, metade dos clubes tinham dirigentes com curso superior completo. É possível ainda destacar o decréscimo da proporção de dirigentes que tinham o menor grau de instrução mensurado (Ensino fundamental Incompleto).

\section{Estado Civil}

Em todos os anos em que a pesquisa foi realizada, a maioria dos dirigentes entrevistada é casada (Tabela 
6). As demais classes não tiveram tanta representatividade em termos de frequência relativa, exceto o grupo Solteiro.

\section{Ocupação Principal}

Com o passar do tempo, nota-se, em relação à ocupação profissional principal (Tabela 7), mudança do perfil dos dirigentes: a maioria deles é ainda funcionário público, embora a proporção tenha diminuído, e tenha havido acréscimo de dirigentes que são empresários. Há flutuação de aumento e queda da proporção nas demais categorias, mas nada que possa ser considerado de maneira satisfatória. Apenas um desses dirigentes se declara exclusivamente como gestor esportivo, identificado na ocupação principal "outra".

\section{Renda mensal pessoal}

Em todos os anos da pesquisa, foi possível observar a predominância de uma alta renda mensal pessoal dos dirigentes na faixa daqueles que recebem mais de US\$1778,31) (Tabela 8). Porém tal grupo teve queda na porcentagem representativa.

Foi possível, ainda, a detecção do aumento da proporção de dirigentes que recebem até US $\$ 355,66$; diminuição da proporção da faixa de US $\$ 711,32$ até US $\$ 1066,98$. Para 2003, U\$\$1 $=\mathrm{R} \$ 2,02$. Para $2004 \mathrm{U} \$ \$ 1=\mathrm{R} \$ 2,19$. Para $2005 \mathrm{U} \$ \$ 1=\mathrm{R} \$ 2,53$. Para 2006 U\$\$ $1=R \$ 2,95$. Para 2007 U\$\$ $1=R \$$ 3,20 . Para chegar a esses valores, foi feita uma média das cotações no $1^{\circ}$ dia e último dia do mês durante os 12 meses do ano.

\section{Cargo no clube esportivo no ano de 2003}

Verifica-se que dentre os dirigentes entrevistados, a maioria em quaisquer anos era o presidente do clube (Tabela 9).

\section{Caracterização do Perfil em 2003}

Para o ano em questão todos os dirigentes eram do gênero masculino, 9/12 casados, metade deles se encontrava na faixa etária de 46 a 55 anos. 10/12 com ao menos segundo grau completo, $5 / 12$ dos dirigentes eram funcionários públicos, e 5/12 também recebiam mais de 1778,31 dólares americanos mensais. 8/12 dos entrevistados exerciam o cargo de presidente dentro do clube.

\section{Caracterização do Perfil em 2004}

Para o ano em questão: 11/12 dos dirigentes eram do gênero masculino, $8 / 12$ casados, $7 / 12$ se encontrava na faixa etária de 46 a 55 anos. 10/12 com ao menos segundo grau completo, um terço dos dirigentes eram funcionários públicos, houve acréscimo na quantidade de dirigentes que são profissionais liberais e 6/12 também recebiam mais de 1778,31 dólares americanos mensais. 9/12 dos entrevistados exerciam o cargo de presidente dentro do clube.

\section{Caracterização do Perfil em 2005}

Para o ano em questão: 11/12 eram dirigentes do gênero masculino, 7/12 casados, 7/12 se encontravam na faixa etária de 46 a 55 anos. 11/12 têm ao menos o segundo grau completo, metade dos dirigentes eram funcionários públicos, e metade também recebia mais de 1778,31 dólares americanos mensais. 11/12 dos entrevistados exerciam o cargo de presidente dentro do clube.

\section{Caracterização do Perfil em 2006}

Para o ano em questão 9/10 dos dirigentes eram do gênero masculino, $6 / 10$ casados, $7 / 10$ se encontravam na faixa etária de 46 a 55 anos. A maioria (7/10) tem ao menos nível superior incompleto, $5 / 10$ dos dirigentes eram funcionários públicos, e 4/10 também recebiam mais de 1778,31 dólares americanos mensais. $8 / 10$ dos entrevistados exerciam o cargo de presidente dentro do clube.

\section{Caracterização do Perfil em 2007}

Para o ano em questão a maioria dos dirigentes era do gênero masculino (7/8), 5/8 casados, $5 / 8$ deles se encontravam na faixa etária de 46 a 55 anos. A metade (4/8) tinha curso superior completo, $3 / 8$ dos dirigentes eram funcionários públicos, e $3 / 8$ também recebiam mais de 1778,31 dólares americanos mensais. 6/8 dos entrevistados exerciam o cargo de presidente dentro do clube.

\section{DISCUSSÃO}

Ao longo dos anos de 2003 e 2007, a proporção de dirigentes analisada reduziu, tendo em vista a redução de clubes participantes das competições nesse período. A frequência absoluta de dirigentes do gênero feminino manteve-se constante desde o ano 
de 2004. Contudo a predominância é de dirigentes do gênero masculino.

Os resultados encontrados neste estudo podem ser diretamente comparados com os obtidos por Azevêdo, Barros e Suaiden( ${ }^{(9)}$, em pesquisa onde foram estudados os dirigentes máximos dos dez clubes que participaram do Campeonato Brasiliense da primeira divisão de futebol profissional, no ano de 2001.

Em relação à idade, pode-se observar que em todos os anos, a concentração de dirigentes estava na classe de 46 a 55 anos, sendo que na passagem do anos de 2006 para 2007 houve uma redução na proporção de dirigentes nessa classe, devido a redução de clubes participantes no ano de 2007. Após 2005 houve um aumento na frequência da classe de idade entre 36 e 45 anos. Azevêdo, Barros e Suaiden (2004) constataram que, em 2001, os dirigentes possuíam, em média, 45 anos e meio, não sendo, portanto, precisar se houve diferença significativa nesta variável. Pires e Lopes(5), concluem que é indispensável uma formação inicial em gestão do desporto, pois a capacitação tradicional já não atende às exigências sociais. Ao longo dos cinco anos pesquisados, constata-se ainda um baixo nível de escolaridade, quando comparado às exigências da área esportiva. $\mathrm{Na}$ pesquisa, sobre o grau de instrução, é interessante observar a inversão das curvas de Ensino médio completo e Curso superior completo. Quando comparados os valores absolutos, de 2003 a 2007 o número de dirigentes com Ensino médio completo decresceu até 2006 tendo um leve aumento em 2007 e o número de dirigentes com Curso superior completo elevou-se até 2005 sofrendo uma leve queda em 2006 mantendo-se em 2007. Apesar dessa redução quando comparados números absolutos, pode-se perceber obteve um aumento relativo do número de dirigentes com Curso superior completo. Entretanto, vale lembrar que o número de clubes que disputaram o ano de 2007 foi reduzido em relação aos outros anos. O que se pode imaginar é a qualificação dos dirigentes que já estavam ocupando o cargo, tendo em vista a pequena troca de dirigentes nos cargos. Já Azevêdo, Barros e Suaiden( ${ }^{(9)}$, verificaram que em 2001, os dirigentes possuíam o ensino fundamental, o que representa uma melhora representativa no nível educacional.
Quanto ao estado civil dos dirigentes, houve uma redução relativa na frequência relativa dos casados e um aumento relativo na frequência relativa de solteiros. Entretanto a quantidade de casados sempre foi superior às outras categorias. Azevêdo, Barros e Suaiden (2004), em pesquisa realizada no ano de 2001, também encontrou predominância de indivíduos casados.

Segundo Drucker(2) e Motta e Bresser-Pereira(3), que entendem que o administrador deva ser um profissional qualificado, especializado em sua área de atuação e que tem seu cargo como atividade principal. A ocupação principal da maioria dos dirigentes esportivos pesquisados é de funcionário público. Um funcionário público, também não atende às competências citadas por Correa ${ }^{(4)}$, tais como: conhecimentos gerais, conhecimentos específicos do ambiente profissional e conhecimentos procedimentais, além de outras competências. Nesta pesquisa ocorreu uma oscilação no número de dirigentes que eram funcionários públicos, entre os anos de 2003 a 2007. Houve um decréscimo do ano de 2003 para 2004, com uma manutenção até 2005 e um aumento em 2006 com novo decréscimo em 2007. Entretanto, esse decréscimo deve ser relativo, pois houve uma redução na quantidade de clubes que disputaram a competição em 2007. Já para o cargo de empresário, houve um aumento de 2003 a 2007, mas nada comparado ao observado para o cargo de funcionário público. A grande maioria acumula sua profissão com as atribuições de dirigente do clube que preside. Apenas um deles se declara exclusivamente profissional de administração de sua entidade de futebol. O resultado corrobora o encontrado por Souza( ${ }^{(8)}$, ao analisar outras entidades esportivas do Distrito Federal, onde os gestores trabalhavam voluntariamente, sem remuneração e dedicando poucas horas por dia às atividades administrativas de sua organização, o que foi considerado insuficiente para a obtenção de êxito.

Azevêdo, Barros e Suaiden( ${ }^{(9)}$ em pesquisa realizada em 2001, também com os dirigentes dos dez clubes que participaram do Campeonato Brasiliense da primeira divisão de futebol profissional, concluíram que eles recebiam mais de US $\$ 2060,53$ por mês. Já no atual estudo, a maior parte dos dirigentes esportivos ganhava entre 2003 e 2007, entre US\$1422,64 a 
mais de US $\$ 1778,31$. Ocorreu, durante os anos, muita oscilação das faixas de salário, exceto a de mais de US $\$ 1778,31$. Nota-se aí, uma redução nos rendimentos desses dirigentes, quando se compara o encontrado na pesquisa realizada em 2001, com o período de 2003 a 2007, com diminuição neste último período.

Nesta investigação, quanto ao cargo, a maioria predominante era de presidentes. $\mathrm{O}$ aumento na frequência relativa de diretores no ano de 2007 pode ser devido a redução do número de clubes naquele ano, pois o aumento absoluto que essa categoria sofreu não foi significativamente alto. Na pesquisa realizada em 2001 por Azevêdo, Barros e Suaiden(9), foram estudados os dirigentes máximos (presidentes) dos clubes participantes do Campeonato Brasiliense.

\section{CONCLUSÃO}

No que se refere à caracterização do perfil sócio-econômico e cultural retrospectivo do dirigente esportivo de clube de futebol profissional da primeira divisão do Distrito Federal, entre os anos 2003 e 2007: É indivíduo do gênero masculino; casado; na faixa etária de 46 a 55 anos; a ocupação principal é de funcionário público; com curso superior completo; renda mensal entre US\$1422,64 a mais de US\$ 1778,31; ocupante do cargo de presidente de seu respectivo clube, sendo apenas um se declara profissionalmente gestor esportivo.

\section{REFERÊNCIAS}

1. Bastos FC (2003). Administração Esportiva: área de estudo, pesquisa e perspectivas no Brasil. Motrivivência Revista de Educação Física, Esporte e Lazer, Universidade Federal de Santa Catarina, Ano XV, no 20 e 21.

2. Drucker PF (2002). Fator humano e desempenho: o melhor de Peter F. Drucker sobre administração. São Paulo: Pioneira Thomson Learning.

3. Motta, FCP, Bresser-Pereira LC (2003). Introdução à Organização Burocrática. São Paulo: Cengage Learning.

4. Correa DKA (2006). As competências no futebol. Seção: Destaque-2. HSM Management Update, $\mathrm{n}^{\circ} 33$, Junho.

5. Pires GMVS, Lopes JPSR (2001). Conceito de Gestão do Desporto. Novos desafios, diferentes soluções. Revista Portuguesa de Ciências do Desporto 1(1): 88-103.

6. Leoncini MP, Silva MT (2005). Entendendo o Futebol como um Negócio: Um Estudo Exploratório. Gestão \& Produção, 12 (1 jan.-abr): 11-23.

7. Zouain DM, Pimenta RC (2003). Perfil dos Profissionais de Administração Esportiva no Brasil. In: Esport Congress, 2003, Barcelona. Anais do Esport Congress, v. 1.

8. Souza RM (2005). Avaliar o grau de amadorismo administrativo de Entidades Esportivas do Distrito Federal, elaborando uma análise da relação entre os investimentos em Marketing e o número de conquistas esportivas. $42 \mathrm{f}$. Projeto Final de Monografia. (Graduação em Administração) - Faculdade de Estudos Sociais Aplicados - Departamento de Administração, Universidade de Brasília, Brasília.

9. Azevêdo PH, Barros JF, Suaiden S (2004). Caracterização do perfil do gestor esportivo dos clubes da primeira divisão de futebol do Distrito Federal e suas relações com a legislação esportiva brasileira. Revista da Educação Física Maringá, 15(01): 33-42.

10. Azevêdo PH (2002). A administração dos clubes de futebol profissional do Distrito Federal em face à nova legislação esportiva brasileira. 183 f. Dissertação (Mestrado em Administração) - Faculdade de Estudos Sociais Aplicados - Departamento de Administração, Universidade de Brasília, Brasília.

\section{CORRESPONDÊNCIA}

\section{Paulo Henrique Azevêdo}

Campus Universitário Darcy Ribeiro

Colina da UnB Bloco H Apto 406

Asa Norte

Brasília - DF - CEP: 70904-108 - Brasil

E-mail: pha@unb.br 